\title{
EDITORIAL
}

\section{Towards defining the lymphoma methylome}

\section{Leukemia (2006) 20, 1658-1660. doi:10.1038/sj.leu.2404344}

'Clay is molded into a vessel, yet is the hollowness that makes the vessel useful.' Tao Te Ching Lao Tzu

Recent genome-wide studies of gene expression and chromosomal aberrations in lymphoid malignancies have significantly extended our understanding of lymphoma pathogenesis and led to the identification and re-definition of lymphoma subtypes, some of them associated with distinct clinical outcomes. ${ }^{1-7}$ Nevertheless, these studies have been mostly focused on the characterization of the tumor-associated genome and transcriptome. In the present issue of Leukemia, Rahmatpanah and co-workers describe a genome-wide partial characterization, focused on CpG-islands, of the methylome of different subtypes of lymphoid neoplasms, and thus, provide an additional step forward towards the molecular characterization of lymphomas.

Genome (i.e. DNA sequence) and transcriptome (i.e. expression of genes) are bridged by epigenetic phenomena like DNA methylation and post-translational modifications of histones, ${ }^{8-10}$ which determine which of the genes encoded in the genome are silenced or expressed in a given cell. The hitherto most widely studied epigenetic alteration in cancer is the methylation of cytosine located in CpG dinucleotides. Most of these CpGs are concentrated in the so-called CpG-islands, many of which coincide with the promoters of protein-coding genes. The methylation status of CpG-islands or specific single CpGs is a key regulator of gene expression. In tumor cells, CpG-islands of tumor suppressor genes are frequently hypermethylated, leading to gene silencing. ${ }^{11,12}$ In contrast, in healthy cells, CpG-islands of tumor suppressor gene loci usually lack methylation, and the gene can exert its function. Remarkably, the cancer genome is hypomethylated on a global level (mostly owing to CpGs in DNA repeats), which might be associated to the marked chromosomal instability in many cancers. ${ }^{13,14}$

The most widely applied methods for detecting changes in DNA methylation of specific genes apply PCR to sodium bisulfite-treated DNA. ${ }^{15}$ However, this methodology is currently limited to the analysis of candidate loci. To overcome this limitation, recent efforts have focused on global epigenomic approaches, which have led to the development and application of a number of different techniques exploiting the potential of microarray technologies ${ }^{16-22}$ (reviewed by Callinan and Feinberg $^{23}$ ). In this context, Rahmatpanah and co-workers describe the application of a CpG-island microarray for the genome-wide characterization of DNA methylation profiles in mantle cell lymphomas (MCLs), B-cell chronic lymphocytic leukemias/ small lymphocytic lymphomas (B-CLLs/SLLs) and low-grade follicular lymphomas (FLs).

The authors identified a total of $256 \mathrm{CpG}$-islands with differential methylation in MCL, B-CLL/SLL and FL. An unsupervised hierarchical clustering unmasked three different groups of lymphomas: one group contained cases in which most CpG-islands were unmethylated, which included all MCLs and a part of the B-CLL/SLLs; another group mostly included FLs and the third group contained B-CLL/SLLs, FLs and benign follicular hyperplasia. A unifying feature of the second and third group was the presence of many hypermethylated CpG-islands. An interesting issue raised by the authors is that differential methylation patterns of B-cell tumors might be related to their cellular origin during B-cell oncogenesis. This hypothesis deserves further investigation on larger studies of well-characterized B-cell malignancies and different normal B-cell populations. In this regard, it is interesting to note that based on gene expression profiling of normal B-cell subsets, the expression of transcripts encoding for DNA methyltransferase I (DNMT1) is significantly higher in normal germinal center B cells (centroblasts and centrocytes) than in normal naive and memory B cells $(P<0.001)$ (own analysis of published data $^{24}$ ) (Figure 1), and than normal mantle zone and marginal zone B cells. ${ }^{25}$

The novelty of the microarray-based methylation techniques currently requires confirmation of the results for individual genes by bisulfite-based PCR approaches. Towards this end, the authors selected 10 genes (ARF4, HOXC10, LHX2, LRP1B, MLLT2, NKX6.1, NRP2, POU3F3, PRKCE and RAMP) with differential methylation and performed methylation-specific PCR (MSP) in primary B-cell lymphomas and B-cell lymphoma cell lines as well as bisulfite sequencing in selected cases. Remarkably, the individual validation by MSP did not strictly correlate with the microarray results. This fact highlights the importance of corroborating microarray data with standard techniques. To further validate the results, the authors also performed RT-PCR analyses of selected genes showing differential methylation. Again, a strict correlation between lymphomaspecific methylation status and gene expression was lacking, although unfortunately different samples were used for both investigations.

Despite the novel insights that the study by Rahmatpanah provides into the lymphoma pathobiology, there are several technical aspects that require attention when interpreting the data. These include the nature of control samples, the method of isolation of methylated sequences and the type of microarray. The characterization of a genome and its variation among individuals is relatively straightforward. However, the characterization of an epigenome is a very demanding task. The Human Epigenome Project is heralding this challenge, and aims to identify, catalogue and interpret DNA methylation among different tissues and individuals. ${ }^{26-28}$ Epigenomic changes can quantitatively vary depending upon tissue type, developmental stage, gender or age. And if that is not challenging enough, epigenetic changes show inter-individual differences and can be influenced by external factors owing to a dynamic and complex interplay between genome and environment. ${ }^{9,28,29}$ Therefore, the issue of which control samples should be used for epigenomic analyses is very important to differentiate epigenetic alterations with functional significance and relevant to cancer development and progression from 'epipolymorphisms'. Rahmatpanah et al. used pooled female or male DNA from peripheral blood samples of seven different healthy individuals with a median age lower than 30 years. This is an appropriate 


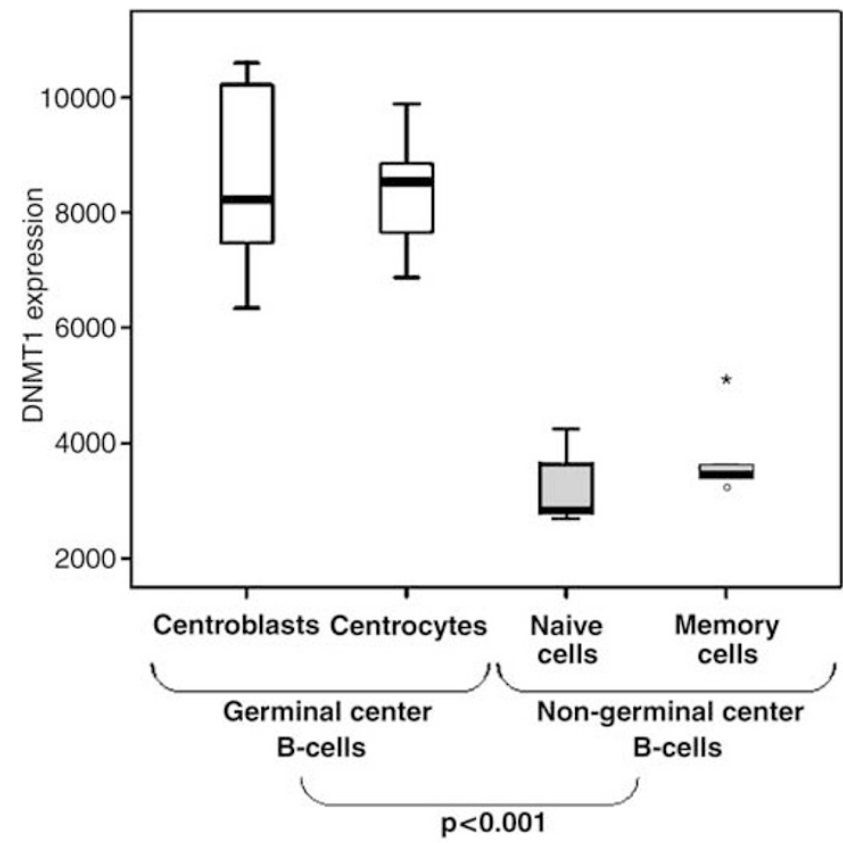

Figure 1 Boxplot diagram of DNMT1 gene expression in different subsets of normal B cells. Based on data published by Küppers et al. ${ }^{24}$

approach to reduce inter-individual and gender-based variability. However, the lymphoma samples used in that study were derived from three different sources, that is, peripheral blood, bone marrow and lymph nodes. It is currently unknown whether these three related, but different, tissues physiologically display considerable epigenomic differences. Additionally, controls and tumor samples were not age-matched, and that can also be a source of epigenetic differences not related with the lymphoma itself. In any case, although the epigenomic variability renders the definition of an ideal control tissue difficult, the use of a matched healthy tissue from pooled individuals with same gender and similar age should be suitable to detect cancer-associated epigenetic differences by microarrays.

Several techniques have been published to analyze the profile of DNA methylation based on microarrays. These include bisulfite treatment, digestion with methylation-specific endonucleases or immunoprecipitation. ${ }^{23}$ The use of methylationspecific enzymes, as performed by Rahmatpanah et al., is limited by the fact that not all CpG-islands contain the enzyme recognition sites. Therefore, not all the $\mathrm{CpG}$-islands in the genome can be interrogated. ${ }^{20}$ An alternative to this approach is the immunoprecipitation of methylated DNA with an antibody against 5-methyl-cytosine (MeDIP technique). ${ }^{21}$ In MeDIP assays, input DNA (i.e. DNA before immunoprecipitation) can be used as reference DNA for the hybridization. Thus, the complete methylome of a single case is determined rather than the differences between a sample and a control. By the direct comparison of immunoprecipitated and input DNAs, the influence of cancer-associated genomic imbalances (e.g. amplifications or deletions) on the amount of immunoprecipitated DNA is reduced. Given the high frequency of chromosomal aberrations in tumor cells, this can be a relevant issue when studying the cancer epigenome. However, a disadvantage of MeDIP in comparison to the enzyme-based approach is that it requires larger amounts of DNA, which can be a limiting factor in cases with low material availability.
With regard to the microarray platform used, those containing oligonucleotides are increasingly substituting bacterial artificial chromosome (BAC)- or CpG-island-based arrays. The resolution of BAC arrays is limited by the size of the BAC (100-200 kb), and only a global epigenetic signature for that large DNA stretch can be obtained, rendering the identification of differentially methylated genes difficult. Arrays based on CpG-island are biased towards those clones contained in the available CpGisland libraries, and therefore, are not representative for the complete genome. In contrast, oligonucleotide arrays, which are commercially available and easily customized according to the user's needs, can reach a very high resolution, for example, of few base pairs along the entire genome if a whole-genome tiling array is used. ${ }^{30,31}$ Nevertheless, so far, there is no 'gold standard' technology for microarray-based epigenomics. A systematic comparison across methods and platforms is urgently needed.

In our opinion, the use of microarray-based strategies is useful to provide a low resolution map of the epigenome, whose proper characterization requires a genome-wide analysis by bisulfite sequencing. The investment of large amounts of resources for bisulfite sequencing of multiple individuals and normal and tumor tissues, as well as the comparison with gene expression data is mandatory to obtain a high resolution map of the cancer cell epigenome.

Studying the methylome is restricted to genes containing CpG-islands, which represent $\sim 70 \%$ of all described genes. ${ }^{32}$ Particularly for genes lacking CpG-islands, examination of the epigenome also requires the study of histone modifications, which also influence gene expression. This can be achieved by chromatin immunoprecipitation with antibodies against specific histone modifications and hybridization onto arrays. ${ }^{30,31}$

The detection of epigenetic changes is not only important for the classification and diagnosis of lymphomas, but also because DNA hypermethylation is an attractive target for DNAdemethylating agents. ${ }^{33}$ In this regard, clinical trials for myeloid leukemias are running. ${ }^{34}$ The application of genome-wide epigenomic studies will allow the identification of hematological neoplasias with high and low levels of CpG-island hypermethylation. It is tempting to speculate that these might show different clinical responses to DNA-demethylating agents. Under this perspective, the data presented by Rahmatpanah and colleagues could suggest that FL (high levels of CpG-island hypermethylation) might respond better to DNA-demethylating agents than MCL (low levels).

In conclusion, the study from Rahmatpanah and colleagues provides first insights into the global methylome of B-cell lymphomas. They identify differentially methylated genes, which might have diagnostic implications and require further investigation. Additional studies on the epigenome will not only help to identify novel cancer-related genes with diagnostic and prognostic value, but also allow a deeper understanding of the mechanisms of carcinogenesis with the aim of developing more effective epigenetic therapies. Furthermore, the combined analyses of genome, epigenome, transcriptome and proteome will allow us, for the first time, to draw an integrated picture of the cancer cell from different perspectives, which indeed will represent a breakthrough in cancer research.

\section{Acknowledgements}

JIMS and RS studies on epigenomics of lymphomas are funded by the 'Deutsche Krebshilfe' and the intramural funds of the Medical Faculty of the Christian-Albrechts University (Kiel, Germany). ME 
and EB are funded by the Health and Science Departments of the Spanish Government and the Spanish Association against Cancer (AECC).

\section{J Martín-Subero ${ }^{1}$, E Ballestar ${ }^{2}$, M Esteller ${ }^{2}$ and R Siebert ${ }^{1}$ ${ }^{1}$ Institute of Human Genetics, University Hospital Schleswig-Holstein Campus Kiel, Kiel, Germany and \\ ${ }^{2}$ Cancer Epigenetics Laboratory, Spanish National Cancer Centre (CNIO), Madrid, Spain E-mail: rsiebert@medgen.uni-kiel.de}

\section{References}

1 Alizadeh AA, Eisen MB, Davis RE, Ma C, Lossos IS, Rosenwald A et al. Distinct types of diffuse large B-cell lymphoma identified by gene expression profiling. Nature 2000; 403: 503-511.

2 Dave SS, Fu K, Wright GW, Lam LT, Kluin P, Boerma EJ et al. Molecular diagnosis of Burkitt's lymphoma. N Engl J Med 2006; 354: 2431-2442.

3 Hummel M, Bentink S, Berger H, Klapper W, Wessendorf S, Barth TF et al. A biologic definition of Burkitt's lymphoma from transcriptional and genomic profiling. N Engl J Med 2006; 354: 2419-2430.

4 Rubio-Moscardo F, Climent J, Siebert R, Piris MA, Martin-Subero JI, Nieländer I et al. Mantle-cell lymphoma genotypes identified with $\mathrm{CGH}$ to BAC microarrays define a leukemic subgroup of disease and predict patient outcome. Blood 2005; 105: 4445-4454.

5 Schwaenen C, Wessendorf S, Kestler HA, Döhner H, Lichter P, Bentz M. DNA microarray analysis in malignant lymphomas. Ann Hematol 2003; 82: 323-332.

6 Staudt LM. Molecular diagnosis of the hematologic cancers. N Engl J Med 2003; 348: 1777-1785.

7 Wessendorf S, Schwaenen C, Kohlhammer H, Kienle D, Wrobel G, Barth TF et al. Hidden gene amplifications in aggressive B-cell non-Hodgkin lymphomas detected by microarray-based comparative genomic hybridization. Oncogene 2003; 22: 1425-1429.

8 Esteller M, Almouzni G. How epigenetics integrates nuclear functions. Workshop on epigenetics and chromatin: transcriptional regulation and beyond. EMBO Rep 2005; 6: 624-628.

9 Jaenisch R, Bird A. Epigenetic regulation of gene expression: how the genome integrates intrinsic and environmental signals. Nat Genet 2003; 33 (Suppl): 245-254.

10 Jenuwein T, Allis CD. Translating the histone code. Science 2001; 293: 1074-1080.

11 Esteller M, Corn PG, Baylin SB, Herman JG. A gene hypermethylation profile of human cancer. Cancer Res 2001; 61: 3225-3229.

12 Herman JG, Baylin SB. Gene silencing in cancer in association with promoter hypermethylation. N Engl J Med 2003; 349: 2042-2054.

13 Ehrlich M. DNA methylation in cancer: too much, but also too little. Oncogene 2002; 21: 5400-5413.

14 Gaudet F, Hodgson JG, Eden A, Jackson-Grusby L, Dausman J, Gray JW et al. Induction of tumors in mice by genomic hypomethylation. Science 2003; 300: 489-492.

15 Herman JG, Graff JR, Myohanen S, Nelkin BD, Baylin SB. Methylation-specific PCR: a novel PCR assay for methylation status of CpG islands. Proc Natl Acad Sci USA 1996; 93: 9821-9826.
16 Adorjan P, Distler J, Lipscher E, Model F, Muller J, Pelet C et al. Tumour class prediction and discovery by microarray-based DNA methylation analysis. Nucleic Acids Res 2002; 30: e21.

17 Ching TT, Maunakea AK, Jun P, Hong C, Zardo G, Pinkel D et al. Epigenome analyses using BAC microarrays identify evolutionary conservation of tissue-specific methylation of SHANK3. Nat Genet 2005; 37: 645-651.

18 Lippman Z, Gendrel AV, Colot V, Martienssen R. Profiling DNA methylation patterns using genomic tiling microarrays. Nat Methods 2005; 2: 219-224.

19 Scholz C, Nimmrich I, Burger M, Becker E, Dorken B, Ludwig WD et al. Distinction of acute lymphoblastic leukemia from acute myeloid leukemia through microarray-based DNA methylation analysis. Ann Hematol 2005; 84: 236-244.

20 Schumacher A, Kapranov P, Kaminsky Z, Flanagan J, Assadzadeh A, Yau $\mathrm{P}$ et al. Microarray-based DNA methylation profiling: technology and applications. Nucleic Acids Res 2006; 34: 528-542.

21 Weber M, Davies JJ, Wittig D, Oakeley EJ, Haase M, Lam WL et al. Chromosome-wide and promoter-specific analyses identify sites of differential DNA methylation in normal and transformed human cells. Nat Genet 2005; 37: 853-862.

22 Yan PS, Wei SH, Huang TH. Methylation-specific oligonucleotide microarray. Methods Mol Biol 2004; 287: 251-260.

23 Callinan PA, Feinberg AP. The emerging science of epigenomics. Hum Mol Genet 2006; 15 (Spec No 1): R95-R101.

24 Küppers R, Klein U, Schwering I, Distler V, Bräuninger A, Cattoretti $G$ et al. Identification of Hodgkin and Reed-Sternberg cell-specific genes by gene expression profiling. J Clin Invest 2003; 111: $529-537$.

25 Shen Y, Iqbal J, Xiao L, Lynch RC, Rosenwald A, Staudt LM et al. Distinct gene expression profiles in different B-cell compartments in human peripheral lymphoid organs. BMC Immunol 2004; 5: 20.

26 Esteller M. The necessity of a human epigenome project. Carcinogenesis 2006; 27: 1121-1125.

27 Jones PA, Martienssen R. A blueprint for a Human Epigenome Project: the AACR Human Epigenome Workshop. Cancer Res 2005; 65: 11241-11246.

28 Murrell A, Rakyan VK, Beck S. From genome to epigenome. Hum Mol Genet 2005; 14 (Spec No 1): R3-R10.

29 Fraga MF, Ballestar E, Paz MF, Ropero S, Setien F, Ballestar ML et al. Epigenetic differences arise during the lifetime of monozygotic twins. Proc Natl Acad Sci USA 2005; 102: 10604-10609.

30 Bernstein BE, Kamal M, Lindblad-Toh K, Bekiranov S, Bailey DK, Huebert DJ et al. Genomic maps and comparative analysis of histone modifications in human and mouse. Cell 2005; 120: 169-181.

31 Lee TI, Jenner RG, Boyer LA, Guenther MG, Levine SS, Kumar RM et al. Control of developmental regulators by Polycomb in human embryonic stem cells. Cell 2006; 125: 301-313.

32 Saxonov S, Berg P, Brutlag DL. A genome-wide analysis of $\mathrm{CpC}$ dinucleotides in the human genome distinguishes two distinct classes of promoters. Proc Natl Acad Sci USA 2006; 103: 1412-1417.

33 Esteller M. DNA methylation and cancer therapy: new developments and expectations. Curr Opin Oncol 2005; 17: 55-60.

34 Issa JP. Optimizing therapy with methylation inhibitors in myelodysplastic syndromes: dose, duration, and patient selection. Nat Clin Pract Oncol 2005; 2 (Suppl 1): S24-S29. 